\title{
Supervision registers: a necessary component of good psychiatric practice
}

\author{
Peter Tyrer and Peter Kennedy
}

Last year Virginia Bottomley announced the creation of supervision registers within a 10 point plan for improving the community care of those of the mentally ill who were at significant risk of self-neglect or a danger to the community. It attracted a storm of criticism from many quarters accentuated by evidence that the new register would be introduced without additional funding. Estimates of between $\$ 70$ million and 5500 million (the latter from the National Schizophrenia Fellowship) were quoted as the necessary expenditure to introduce the scheme and the despair at this announcement was best lllustrated by $a$ cartoon (in the Independent newspaper) showing a psychiatrist experiencing imperative auditory hallucinations of Mrs Bottomley's voice saying simultaneously "do more" and "no more money".

The lack of resources for the new register has been the most prominent criticism and Holloway's fear that the introduction of supervision registers may be "a mistaken policy that yet again proposes a bureaucratic solution to what is essentially a problem of inadequate resources" (Holloway, 1994) is shared by the College (Caldicott, 1994). In addition there are powerful concerns over the lead responsibilities of consultants and keyworkers, confidentiality, the effects of the register on therapeutic relationships, the implications of the inclusion of personality disorder and time constraints in the operation of the register.

It was obvious more than 15 years ago that a dispersed community based service needed care planning protocols for most discharged patients and supervision arrangements for a minority. Academics dallied with case registers which produced interesting data (Gibbons et al 1983) but were never linked to the realities of clinical practice and daily management of services. True, a few centres developed monitoring or tracking systems for the severely mentally ill but they were generally ignored by the majority. Now we are suffering the humiliation of having the mandarins and boffins of the Department of Health telling us

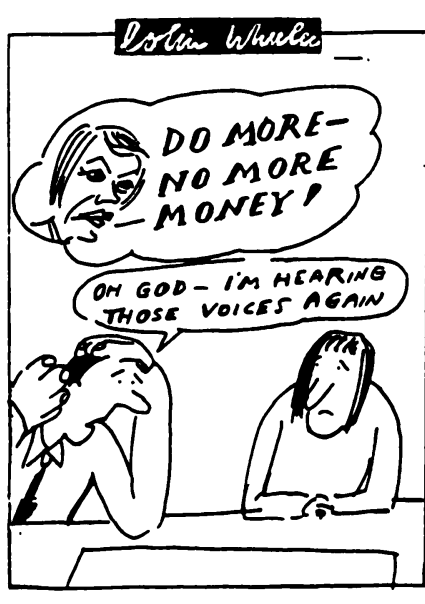
how to do it in the form of the care programme approach (CPA) and the introduction of the supervision register.

To blame government policy for community care is to deny our individual responsibilities as psychiatrists: we discharged the patients, not the Secretary of State. When she responds to our criticisms of supervision registers by asserting "if community care is to work for the most severely mentally ill patients it is essential that responses are targeted effectively" (Bottomley, 1994) she is only saying what many of us have argued for years. The argument that we lack resources for effective community care is weakened by the fact that we have shown so little interest in standardised planning procedures for identifying the number of severely mentally ill in every district, their needs, the gaps in service, and the risks being carried by frontline staff. This is basic information which would be requested by anyone concerned with public health and priorities for funding. This is one of the main purposes of the CPA and supervision register. The absence of these 
procedures over the last decade has meant inefficient, poorly targeted mental health resources, which are distributed independently of apparent need (Hirsch. 1988) and with a low level of confidence that further investments will reach those whose needs are greatest. The Audit Commission (Renshaw, 1994) certainly gives us no reassurance that our current resources are being targeted always in a sensible and clinically appropriate way.

Although we have worried about ctvil rights and the stigmatisation of patients on registers we contradict ourselves by arguing that the same patients should be back in the mental hospitals which originally deprived them of ctvil rights and heightened stigma. Meanwhile, we may have failed to notice the pendulum swinging towards greater public concern for the rights of those at risk, like $\mathrm{Mr}$ Zito who died at the hands of Christopher Clunis.

If we did not have the present guidance on CPA, which is now increasingly in tune with clinical needs (Kingdon, 1994) and supervision registers we would have to invent something almost identical. There is no doubt that had the profession got to grips with the issue 15 years ago, we would have developed, more collaborattively and with less need for haste, a similar system. The resources would have been targeted better, and the severely mentally ill would have been better managed. It is hard to explain to the man or woman in the street what are the alternatives to having something like the CPA and supervision register. Certainly the present system is no defence.

But it is never too late. This long overdue birth of a fraglle infant could be assisted by the profession and reared into something that is really helpful to patients, mental health key-workers and planners. We are seeking the glue that will hold together all the components of care for those people who cannot hold them together for themselves, and no longer have a mental hospital to do it for them. We will not gain respect if we continue to bicker over the costs of implementing the new register and scoring easy debating points against a Secretary of State who, whatever her apparent failings, has a genuine interest in the care and welfare of the psychiatric patient.

The register, if properly used, is a powerful tool for negotiating the proper level of investment by identifying the number, needs, gaps in provision, and risks to the community.
As a means of sharing risk between psychiatrist, trust management, and health authority, it avoids scapegoating for front-line professionals when things go wrong, as inevitably they will no matter how much supervision we give patients.

Some kind of register is the only way of tracking itinerant patients with recurrent psychotic illness across district borders, and so ensuring continuity of responsibility for funding their care. Psychiatrists know better than anyone that it is the natural history of those people with severe psychosis to drift into the anonymity of big cities, and to be transient residents in unstable accommodation. We should feel ashamed that we have not taken the lead in working out how to track them effectively.

Instead of feeling the need to argue every detall in the guidance given to us by the Department of Health on supervision registers (like bureaucrats who can only respond to the written instruction) we need to take the guidance as it is, adapt, develop, change and improve it, to make it work for us and our patients. If we do this resources will be better targeted and, even if the total is not increased, more will be given to those who need it most but demand it least.

\section{References}

BotromuEY, V. (1994) Supervision registers: the College's response. Reply from Secretary of State. Psychiatric Bulletin, 18, 387-388

Caldicort, F. (1994) Supervision registers: the College's response. Psychiatric Bulletin, 18, 385-386.

Grbeons. J. L, Jennnnos, C. \& Whv, J. K. (1983) Psychiatric care in eight register areas: statistics from eight psychiatric case registers in Britain, 1976-81. In Southampton Psychiatric Case Register, Knowle Hospital, Fareham. Hants.

HIRSCH, S. R. (1988) Psychiatric Beds and Resources: factors for influencing bed use in service planning. London: Gaskell (Royal College of Psychlatrists).

Houloway, F. (1994) Supervision registers: recent government policy and legislation. Psychiatric Bulletin. 18, 593-596.

KINGDON. D. (1994) Care programme approach: recent government policy and legislation. Psychiatric Bulletin. 18, 68-70.

Renshaw, J. (1994) The Audit Commission's view of mental health services. Psychiatric Bulletin, 18, 421-422.

PETER TYRER, Professor of Community Psychiatry, St Charles' Hospital, London W10 6DZ; and PETER KENNEDY, Chief Executive York Health Services NHS Trust, Bootham Park, York 